\title{
REASONS FOR ATTENDING A MOOC: A SURVEY ON EDUOPEN LEARNERS
}

\author{
Annamaria De Santis, Katia Sannicandro, Claudia Bellini, Tommaso Minerva, University of \\ Modena and Reggio Emilia, Italy
}

\section{Introduction}

In the Italian university context, starting from 2016, EduOpen portal (https://learn.eduopen.org) was launched. It was realized within a project funded by the Italian Ministry of Education, University and Research (MIUR) for an extraordinary intervention based on art. 11 of the Ministerial Decree of November 4 n. 815 (distribution of the Ordinary Financing Fund). The MOOC platform is made up of 17 Italian universities and a set of selected partners; the network is open to the access of other universities and institutions, associations of scientific and cultural relevance.

The registered users are about 50,000 (February 2019). Till now, 208 courses and 26 pathways (training courses dedicated to the construction of complex knowledge and composed by multiple MOOCs and intermediate and final assessments) were produced. At the completion of each course the user acquires an attendance certificate and an open badge (currently distributed by Bestr, www.bestr.it). Moreover, users can acquire ECTS by attending EduOpen MOOCs: there are two Professional Masters and some curricular courses that provide academic credits for students that formalize the enrolment at the reference universities of the network. 


eduQpen courses Pathways Masters courseware os

\section{FREE [THE] KNOWLEDGE FOR EVERYONE}

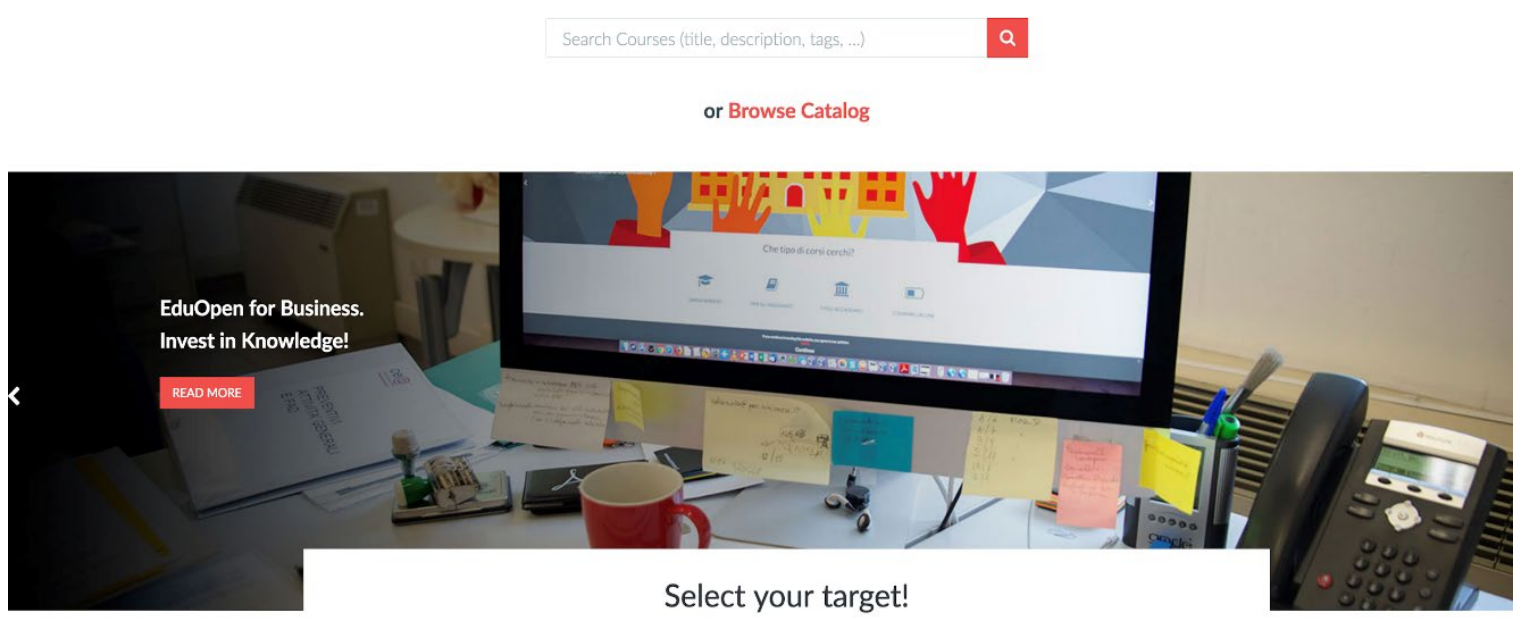

Figure 1. EduOpen Homepage - https://learn.eduopen.org

The continuous development of the project concerns not only the access of new universities and the consequent initiatives - such as the activation of Professional Masters as MOOCs, first in Italy - but also the constant increasing of the number of registered students in EduOpen. It requires updating of the user interface and technical functions, together with a reflection on the instructional design based on users' training needs.

The paper shows an early analysis of the training needs of users enrolled in the courses on EduOpen through the study of motivations that lead them to register in the portal and, so, to enrol in training paths offered in open mode in the Italian context (especially in the EduOpen environment). We start a reflection on users' expectations and on the reasons for drop out. In a wide research perspective, the analysis conducted will help us to understand how students use the portal and reply to the following research questions: how to promote the continuous development of skills related to the professional expectations of EduOpen users? Which can be effective tools and strategies for rethinking the instructional design of the courses, starting from the training needs of the users?

\section{Methods}

The tool used for the research consists of a questionnaire of 35 queries of which two openended and 33 with closed answers. The survey, designed to define the characteristics, the motivations and the kind of portal use by registered users, is divided into two areas. The first part (18 closed questions) focuses on defining the users' personal data; the second part (13 closed questions and 2 open questions) focuses on: the level of digital competence (declared and perceived); reasons to enrol and abandon the courses; devices and softwares used to navigate the pages in the platform; registration on other national and international MOOC platforms; most appreciated course topics; number of completed courses and badges acquired; satisfaction in using EduOpen. 
The following section describes the answers to 3 questions belonging to the second part of the questionnaire that allow to define motivations, expectations and needs of the users. We investigate the reasons that push to register in an open portal along with those that lead to abandoning courses that are attended free and voluntary. At the same time, we aim to verify the interest shown for the topics of study (categories) in which the courses on EduOpen are grouped, describing the themes that, being the focus of the attention of the students, can be considered indicative of their training needs. The results obtained from the analysis of the three questions are presented in relation to the survey data obtained from the first part of the questionnaire and already presented in other works (De Santis et al., 2018).

\section{Results}

The questionnaire was answered by 1982 users, that is $6.6 \%$ of those enrolled when the survey was launched. To date, no sample significance testing has been conducted, but the high number of answers qualitatively supports the hypothesis that the sample is significant and representative of the whole population.

The analysis carried out on the users' personal data, that we can read in the first part of the questionnaire, shows some features of EduOpen users, partly in common with the international descriptions related to learning environments that offer MOOCs (OECD, 2017). The users are mainly adults: $49.5 \%$ of respondents are of age 45 to 64 and $59.7 \%$ of the sample completed at least a bachelor's degree.

Referred to occupational and marital status, survey reveals that $62.7 \%$ of users attending courses on EduOpen are employed, $15.0 \%$ occasional workers, a further $14.5 \%$ unemployed:

- the first ones (employed) are adults over the age of 40, mainly married/cohabiting, with an educational attainment equal or higher than the master's degree (58.5\%);

- the second ones (occasional workers) are under the age of 40 years, attending university (both undergraduate and graduate) courses and $56.5 \%$ have an educational qualification equal or lower than bachelor's degree, $40.2 \%$ are married/cohabitant;

- the third ones (unemployed) are single, in education, under the age of 30, with a secondary (51.1\%) and tertiary (44.7\%) educational qualification.

These elements are used in this paper to analyse the answers to the three questions selected for the discussion; they allow us to read more deeply into the results obtained.

Table 1 shows the reasons that led the users to register in EduOpen. The main options selected are training needs (65.7\%) and interest in course topics (44.9\%). Continuing, we found the need for professional updating (37.3\%), the possibility of using open and free materials (30.4\%) and obtaining certification for the courses attended (28.7\%). We analyse these data through some categories used to describe the demographic features: age, employment status, marital status. The main evidences emerged are below: the mode for all the categories analysed is the answer: "for my training needs, I would like to acquire/improve my knowledge and skills". 


\section{Age}

Less than 40 years old $(\mathrm{N}=676)$; more than 40 years old $(\mathrm{N}=1173)$.

Dividing the sample by age into two groups (the central value - 40 years - was chosen starting from the demographic and occupational elements previously described), the main differences are noted in correspondence of the following response options:

- "for professional updating" - $28.1 \%$ for under $40,42.6 \%$ for over 40 ;

- "to obtain certifications" - $32.1 \%$ for under $40,26.8 \%$ for over 40 ;

- "to complete my university training" - $19.4 \%$ for under $40,5.2 \%$ for over 40 ;

- "at the suggestion of the teachers of my degree course/of my school" - $13.3 \%$ for under $40,1.4 \%$ for over 40 .

In line with these results, the users aged under 40 years old, mostly unemployed or occasional workers, are university students and need certification of acquired skills; instead, the over 40s - that are employed -, are more interested in professional training courses.

\section{Employment Status}

Unemployed $(\mathrm{N}=263)$; occasional workers $(\mathrm{N}=271)$; employed $(\mathrm{N}=1146)$.

In the same way, also in this categorization, the answer options with more relevant variations are: "for professional updating" with values respectively for the three groups equal to $19.4 \%$, $33.6 \%$ e $44.9 \%$; "at the suggestion of the teachers of my degree course/of my school" with $16.0 \%, 11.4 \%, 2.2 \%$; "to complete my university training" with $22.4 \%, 15.5 \%, 5.8 \%$. A slight variation, not appreciable in the other two demographic categories, is related to the response: "to attend courses offered by universities that in my opinion work seriously and effectively". This option is more frequently observed among workers (occasional $22.1 \%$, employed $23.1 \%$ ) than unemployed (17.5\%).

\section{Marital Status}

Married/cohabiting with children $(\mathrm{N}=695)$; married/cohabiting without children $(\mathrm{N}=401)$; no married/cohabiting $(\mathrm{N}=726)$.

A new confirmation in the correspondence between reasons of registrations and personal data comes from this categorization where the variations regard the options: "for professional updating", "at the suggestion of the teachers of my degree course/of my school", "to complete my university training". The percentages of married/cohabitants with children interested in the professional updating amount to $42.7 \%$, the percentages for married/cohabitant without children is $42.9 \%$, for singles the value drops to $29.2 \%$. The university training is a reason for registration in the portal for $16.4 \%$ of no married/cohabitants and for $6.2 \%$ of married users with children, $6.7 \%$ for married without children. The teachers' suggestion is essential for $11.8 \%$ of singles, only $1.4 \%$ of married with children, $2.5 \%$ of married without children. Comparing the trends of the two distributions for the conjugates (with and without children) there were no relevant changes in the resulting percentages (among the no 
married/cohabitants it was preferred not to distinguish the data relating to users with and without children because the number of singles registered at the portal that have children is very low).

Table 1: You decided to register in EduOpen... (max 3 answers) $-\mathrm{N}=1850$

\begin{tabular}{lc}
\hline Reasons to register to EduOpen & $\%$ users \\
\hline $\begin{array}{l}\text { for my training needs, I would like to acquire/improve my knowledge and } \\
\text { skills }\end{array}$ & $65.7 \%$ \\
for curiosity/interest in the topics of the courses & $44.9 \%$ \\
for professional updating & $37.3 \%$ \\
to learn free, open and online materials & $30.4 \%$ \\
to obtain certifications & $28.7 \%$ \\
to attend courses offered by universities that in my opinion work seriously & $21.8 \%$ \\
and effectively & \\
to learn by overcoming geographical limits & $12.9 \%$ \\
to complete my university training & $10.4 \%$ \\
to join a learning community on the topics of my interest & $9.8 \%$ \\
for a professional reorientation & $8.1 \%$ \\
at the suggestion of the teachers of my degree course/of my school & $5.8 \%$ \\
to attend courses by one or more teachers I like & $4.0 \%$ \\
at the suggestion of my director/manager & $1.0 \%$ \\
other & $2.0 \%$ \\
\hline
\end{tabular}

The main interests of EduOpen users regard "Social sciences, Computer and data sciences, Arts and humanities" (see Table 2). We present the training needs of users starting from the categorization of courses topics based on users' personal data. If we categorize the data with reference to age and marital status, the trends are not very discordant. Instead, the histograms in Figure 2, 3 and 4, show the most significant variations obtained by grouping data by gender, employment situation and educational attainment. Women prefer courses about Social sciences and "Arts and humanities" more than men that, on the other hand, are more interested in "Computer and Data Sciences, Technologies, design and engineering" and "Science". "Computer and data sciences", as well as "Social Sciences", are the areas in which the most relevant differences occur based on the employment situation. Frequency trends, if the educational attainment is considered the variable, are quite changing: users with a secondary education qualification are interesting in courses regarding "Computer and data sciences" and "Social sciences"; users with a degree or over are interested in "Social sciences" and "Arts and humanities".

Table 2: $\quad$ EduOpen courses are divided into 6 topics (categories). Which of these are you most interested in? (more answers possible) - N $=1788$

\begin{tabular}{lc}
\hline Course categories & $\%$ users \\
\hline Arts and humanities & $41.2 \%$ \\
Computer and data sciences & $42.8 \%$ \\
Health and pharmacology & $15.0 \%$ \\
Science & $29.0 \%$ \\
Social sciences & $53.9 \%$ \\
Technologies, design and & $23.8 \%$ \\
engineering & \\
\hline
\end{tabular}




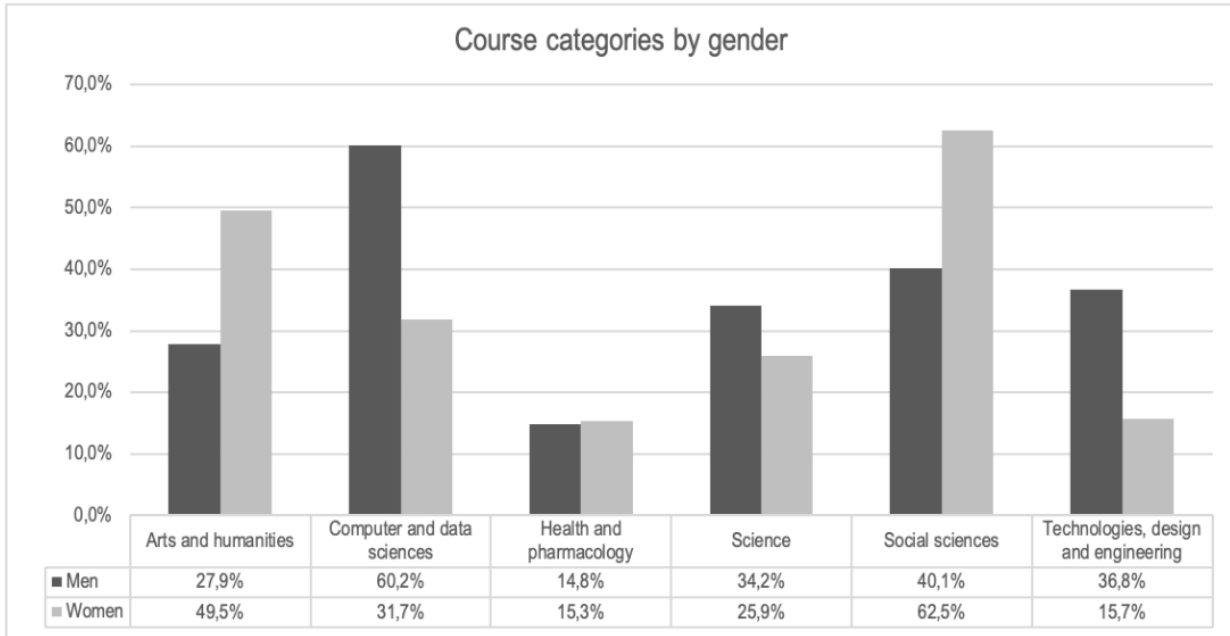

Figure 2. Course categories by gender

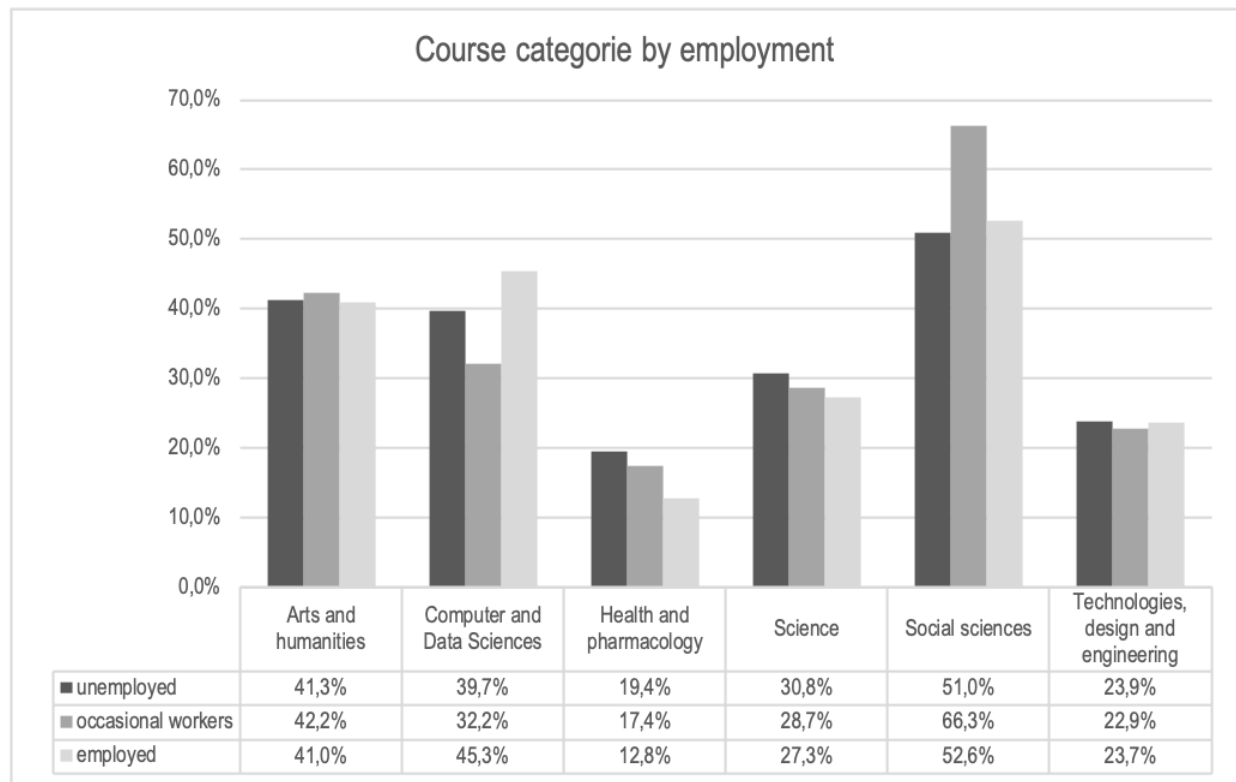

Figure 3. Course categories by employment

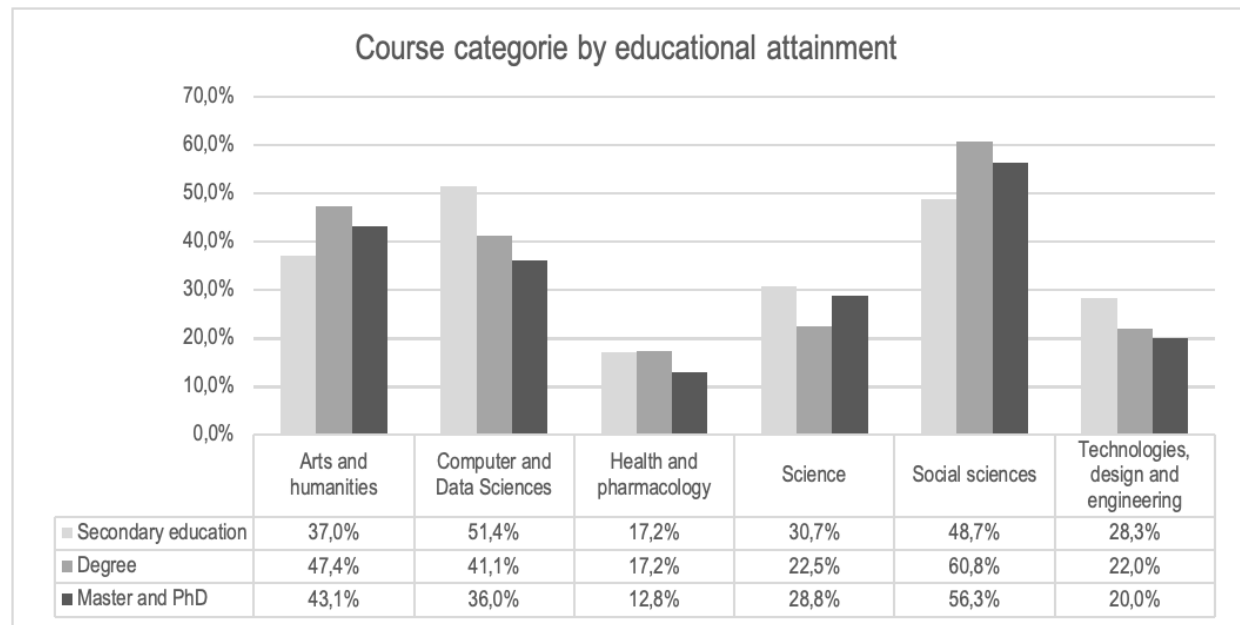

Figure 4. Course categories by educational attainment 
Last issue in our discussion regards the reasons for users drop out of courses. Table 3 shows that for almost all items, adding the percentages calculated for the two positive options (agree and completely agree) and for the two negative ones (completely disagree and disagree), the population tends not to consider as relevant for dropping out a course the unsatisfactory interaction with classmates $(83.7 \%)$ and with instructors $(64.6 \%)$, the use of a transmissive teaching method $(63.2 \%)$, the presence of demanding tasks $(58.2 \%)$, difficult in navigation of the platform (54.5\%). The sample is divided into two groups of almost similar size on the items referred to audio-visual quality of the teaching materials $(52.3 \%)$ and the definition of deadlines for assessments (50.8\%). The only two items for which the percentages of disagreement are below 50\% are related to instructional design of the course $(45.6 \%)$ and personal commitments (22.6\%).

Table 3: Which of the following reasons could push you or (pushed you in the past) to drop out a MOOC? - N = 1602

The answers to each item were structured on a 4-level Likert scale: 1 - completely disagree, 2 - disagree, 4 -agree, 5 - completely agree

\begin{tabular}{|c|c|c|c|c|}
\hline Reasons to drop out a MOOC & 1 & 2 & 4 & 5 \\
\hline unsatisfactory interaction with classmates & $52.1 \%$ & $31.6 \%$ & $12.7 \%$ & $3.6 \%$ \\
\hline $\begin{array}{l}\text { unsatisfactory interaction with instructors (communication, } \\
\text { support, feedback) }\end{array}$ & $35.7 \%$ & $28.9 \%$ & $28.0 \%$ & $7.4 \%$ \\
\hline $\begin{array}{l}\text { inadequacy of the instructional design of the course (structure, } \\
\text { materials, activities) }\end{array}$ & $25.4 \%$ & $20.2 \%$ & $33.3 \%$ & $21.1 \%$ \\
\hline dema & $23.7 \%$ & $34.5 \%$ & $33.4 \%$ & $8.4 \%$ \\
\hline defir & $18.9 \%$ & $31.9 \%$ & $37.5 \%$ & $11.6 \%$ \\
\hline use c & $25.3 \%$ & $37.8 \%$ & $29.0 \%$ & $7.9 \%$ \\
\hline latform & $30.0 \%$ & $24.5 \%$ & $29.7 \%$ & $15.8 \%$ \\
\hline $\begin{array}{l}\text { inadequate audio-visual quality of the teaching materials } \\
\text { published in the course }\end{array}$ & $27.2 \%$ & $25.1 \%$ & $30.8 \%$ & $16.9 \%$ \\
\hline unforeseeable personal commitments & $9.9 \%$ & $12.8 \%$ & $42.2 \%$ & $35.0 \%$ \\
\hline
\end{tabular}

Some reflections:

- It's relevant that an unsatisfactory interaction with colleagues doesn't represent a valid reason to stop attending a course. The result is in contrast with some recent researches that explored the online textual interactions between users, concluding that, even today, connections among tutors, staff and peers represent the most important support for learning (Reich \& Rupierez-Valiente, 2018; Xu et al., 2018). On the contrary, it supports the hypothesis that the motivations of EduOpen users have a predominantly intrinsic connotation. The factor is confirmed by the answers to question Q21 in which the highest percentages of reasons for registering to the portal are referred to training needs, interest and curiosity in the topics and not, among those proposed, to joining in learning communities.

- The instructional design is an issue of interest for users enrolled in the courses. The term instructional design is not used as a synonym of active or collaborative teaching methods by users. In fact, the use of a transmissive teaching method, distinguishing of 
the so-called xMOOCs, is not considered by over $60 \%$ of users as a valid reason to drop out the courses.

- The opinions of users about the navigation of the platform and the production of multimedia materials are mostly equally divided into critical and uncritical. The data will have to be analysed in relation to the questions that define the digital skills and the number of completed courses by the students.

\section{Conclusions}

The analysis conducted shows the below main elements:

- the main reasons for registration of EduOpen learners are to be found in a personal training needs and curiosity/interest in the topics of the courses;

- the learners don't see in the interaction with classmates a motivation that lead them to leave participation in a course;

- users place greater emphasis on interaction with teachers than one with classmates and on a friendly interface.

Despite these results - we believe in the relevance of peer-interaction in online learning context - we recently stimulated a learning users' community where we invite learners to be involved as mentor, a facilitator profile who will try to support and increase communication among the students.

The trends emerged from the answers about the instructional design of the courses opened a discussion on the profile of the EduOpen's Instructional Designers, technological tools and teaching strategies that allow to realize courses starting from the training needs of the users. We pursue this goal in agreement with recent research highlighting that demonstrate close link between design, development of teaching strategies and learning processes in MOOCs (Jung \& Lee, 2018).

\section{References}

De Santis, A., Sannicandro, K., Fazlagic, B., Bellini, C., Tedeschi, C., \& Minerva, T. (2018). Gli Open Learners di EduOpen: numeri e prospettive. In A. Volungeviciene, \& A. Szücs (Eds.), Exploring the Micro, Meso and Macro. Navigating between dimensions in the digital learning landscape. EDEN 2018 Annual Conference, Genoa, Italy 17-20 June 2018 (pp. 88794). Budapest: European Distance and E-Learning Network.

Jung, Y., \& Lee, J. (2018). Learning engagement and persistence in massive open online courses (MOOCS). Computers \& Education, 122, 9-22.

OECD (2017). Education at a Glance 2017: OECD indicators. Paris: OECD Publishing. Retrieved http://dx.doi.org/10.1787/eag-2017-en

Reich, J., \& Rupérez-Valiente, J. A. (2018). The MOOC Pivot. What happened to disruptive transformation of education? Science, 363(6423), 130-131. 
Reasons for Attending a MOOC: A Survey on EduOpen Learners

Annamaria De Santis et al.

Xu, D., Solanki, S., \& McPartlan, P. (2018). EASing students into college: the impact of multidimensional support for underprepared students. Sage journals, 7(47), 435-450. 